\title{
Prediction of load on the cutting tools in tunnel boring machines
}

\author{
Józef JONAK ${ }^{1}$, Ivan KURIC ${ }^{2}$, Pawel DROŹDZIEL ${ }^{3}$, Jakub GAJEWSKI ${ }^{\text {* }^{*}}$ \\ and Milan $\boldsymbol{S A G A ^ { 4 }}$
}

Authors' affiliations and addresses:

${ }^{1}$ Lublin University of Technology, Faculty of Mechanical Engineering, Department of Machine Design and Mechatronics, Nadbystrzycka 36 Str., 20-618 Lublin, Poland

e-mail: j.jonak@pollub.pl

${ }^{2}$ University of Žilina, Faculty of Mechanical Engineering, Department of Automation and Production Systems, Univerzitná 8215/1, 01026 Žilina, Slovakia

e-mail: ivan.kuric@fstroj.uniza.sk

${ }^{3}$ Lublin University of Technology, Faculty of Mechanical Engineering, Institute of Transport, Combustion Engines and Ecology,

Nadbystrzycka 36 Str., 20-618 Lublin, Poland e-mail: p.drozdziel@pollub.pl

${ }^{4}$ University of Žilina, Faculty of Mechanical Engineering, Department of Applied Mechanics, Univerzitná 8215/1, 01026 Žilina, Slovakia e-mail: milan.saga@fstroj.uniza.sk

\section{*Correspondence:}

Jakub Gajewski, Lublin University of

Technology, Faculty of Mechanical Engineering, Department of Machine Design and

Mechatronics, Nadbystrzycka 36 Str., 20-618

Lublin, Poland

tel.: +48815384202

e-mail: j.gajewski@pollub.pl

Funding information:

Ministerstwo Nauki i Szkolnictwa Wyższego,

Poland

\section{Acknowledgement:}

The project/research was financed in the framework of the Project Lublin University of Technology - Regional Excellence Initiative, funded by the Polish Ministry of Science and Higher Education (contract no.

030/RID/2018/19).

How to cite this article:

Jonak, J., Kuric, I., Droździel, D., Gajewski, J and Saga, M. (2020). Prediction of load on the cutting tools in tunnel boring machines. Acta

Montanistica Slovaca, Volume 25 (4), 444-452

DOI:

https://doi.org/10.46544/AMS.v25i4.01

\begin{abstract}
A tunnel boring machine (TBM) is a machine that is used to excavate tunnels with a circular cross-section. TBMs can bore through a variety of ground conditions. Tunnel boring machines are used as an alternative to drilling methods. TBMs have the advantages of limiting the disturbance to the surrounding ground. Predicting the load on cutting tools in tunnel boring machines is important for the mining process. The article presents a proposal for a method of forecasting the load on mining machinery tools. This paper presents current trends in hard rock tunnelling, including the directions of research on automated excavation processes. Particular emphasis is put on the aspects of predicting load variations in the cutterhead tools, which is of vital importance for machine power selection and mining process control, among others.

The problem of predicting the load and wear of excavation tools plays an important role in designing and maintaining cutterheads. The effective monitoring of the operation of multi-tool cutterhead knives and their replacement time depend on correct identification of the type and condition of the excavating tool cutting insert.

A neural network with a multilayer perceptron structure was used as a prediction tool. The concept of this network type is based on the arrangement of neurons in successive layers. This neural network type is treated as an input-output model. Its parameters include weights and threshold values.
\end{abstract}

\section{Keywords}

tunnel boring machines, neural network, mining tools 


\section{Introduction}

Underground transport tunnels are nowadays constructed primarily by hard rock mechanical mining using two basic techniques. One of them is based on the use of so-called tangential tapered rotary cutters as mining tools (Fig. 1b), while the other involves the use of disc cutters (Fig. 2). (Krauze and Bołoz et al., 2015; Bołoz, 2018; Bołoz and Midor, 2018, 2019; Hasilová and Gajewski, 2019; Jedliński and Gajewski, 2019, Bołoz, 2020)
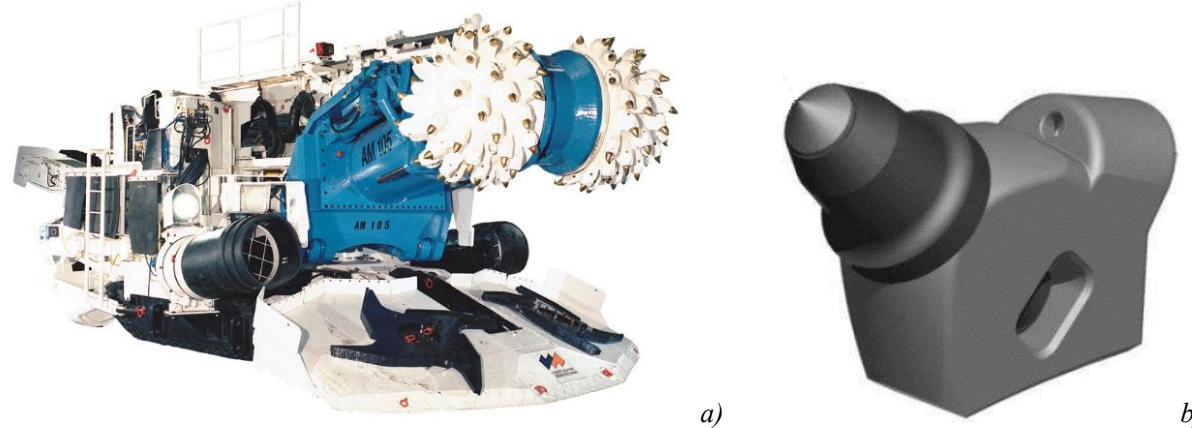

Fig. 1. Roadheader with tangential rotary cutters mounted in the cutterhead

b)

Two types of disc cutters are generally used: symmetric (predominantly in tunnel boring machines) and asymmetric (Fig. 2), the latter being a recent trend.
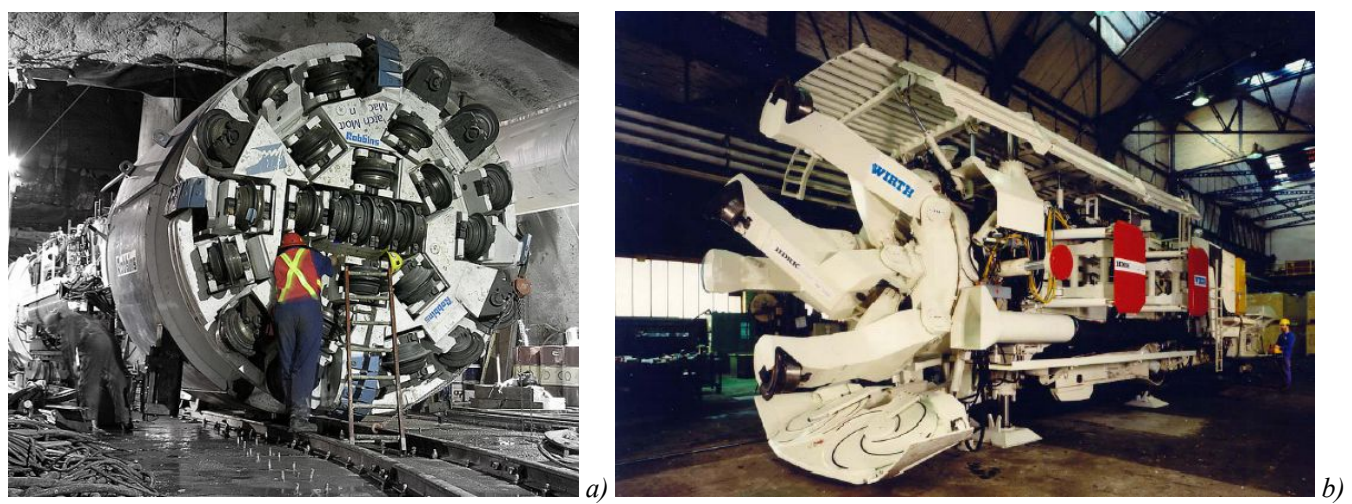

Fig. 2. Tunnel boring machine (TBM) with symmetric disc cutters (a), Aker Wirth tunnel-boring machine equipped with "undercutting" asymmetric disc cutters (b)

Due to the growing traffic in cities, alternative underground transport routes are required. An effective and relatively fast method for solving these problems is to construct transport tunnels using full-face excavation TBMs. One of the largest disc cutter to date (19.25 meters in diameter) was used in the construction of a tunnel under River Neva in St. Petersburg.

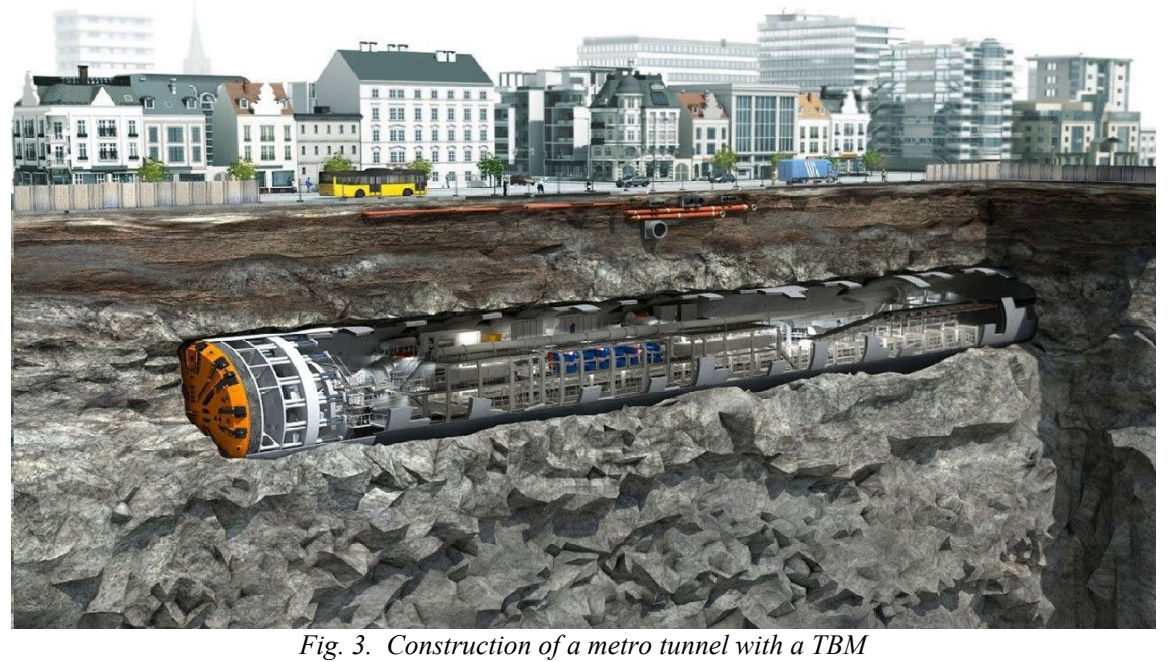

[https://medium.com/netive-in/17th-tunnel-boring-machine-lowered-for-metro-iii-tunnel-work-1c5f7360af29] 
In Poland, TBMs were first used to bore the tunnel of the second line of the Warsaw Metro. Later on, these machines were used for constructing a road tunnel under the Dead Vistula River in Gdańsk. Recently, a contract has been signed for the delivery of two TBMs to Łódź, where an underground railway line between Łódź Fabryczna and Łódź Kaliska / Łódź Żabieniec is being built. One of these machines will be the largest one ever used in Poland.

Despite the enormous advantages of TBMs and a wide spectrum of applications for these machines in various mining and geological conditions, it is sometimes necessary to use traditional yet significantly modified boring techniques. Given the fact that tunnel excavation cross-sections are becoming bigger and bigger and thus exceed the operational capabilities of partial-face excavation machines, the excavation must be performed sequentially, as shown in Fig. 4. According to this excavation technique, which is known as the sequential excavation method or the New Austrian tunnelling method (NATM), the tunnel is sequentially excavated and supported [Clarke-Hackston N. , Belz J., Henneker A.: Guidance for Partial Face Excavation Machines. 1st International Conference on Machine Control \& 2008. http://citeseerx.ist.psu.edu/viewdoc/download?doi=10.1.1.537.6197\&rep=repl\&type=pdf ].
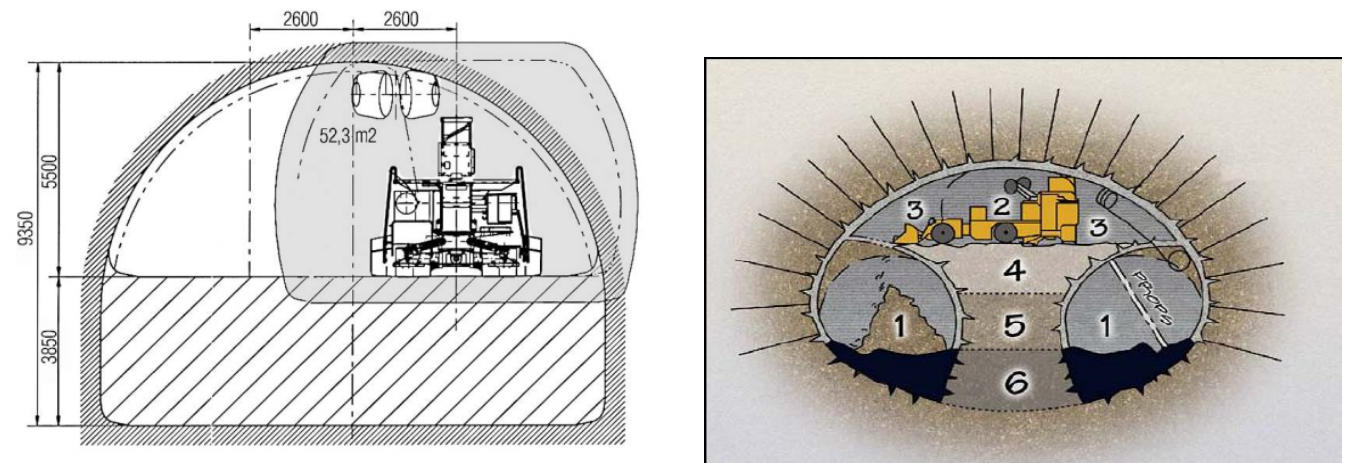

Fig. 4. Sequential excavation method [Route 710 Tunnel Technical Feasibility Assessment Report. Task Order PS-4310-1268-05-01-2. Submitted to: Metro, Los Angeles County Metropolitan Transportation Authority One Gateway Plaza Los Angeles, CA 90026 MS 99-22-8 Submitted by : Parsons Brinckerhoff, June 7, 2006. http://media.metro.net/images/710_final_report.pdf]

In such situations, traditional manual control methods of the boring process by the operator are insufficient due to the necessity of maintaining the required tunnelling direction throughout the entire excavation and ensuring the required shape and dimensions of the excavation.

Due to both the reasons mentioned above and the need for reducing the number of miners working in the face areas of high risk and unfavourable microclimate (elevated temperature and humidity at high depths), tunnel excavation using roadheaders must be automated.

This, however, can be accomplished if two basic problems are solved. The first problem relates to maintaining the assumed direction of tunnelling or excavation as well as monitoring the position of the roadheader relative to the excavation (machine navigation). The other problem concerns the optimal performance-efficient control of the cutterhead trajectory to ensure that the shape and dimensions of the excavation are within acceptable limits. It is also necessary that the cutterhead trajectory can be generated by a programmable logic controller (PLC), a tool that is widely used in process automation. The cutterhead trajectory recommended in literature as optimal with respect to excavation process automation feasibility is shown in Fig. 5 .

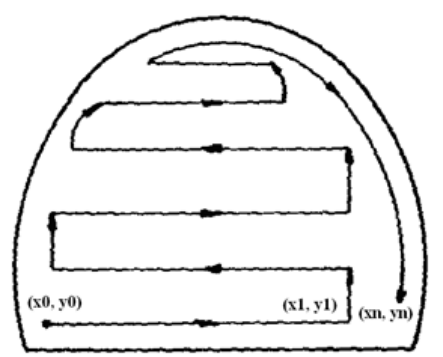

Fig. 5. Cutterhead trajectory identified as optimal in terms of machinery performance and excavation process automation

Leading global companies, e.g. Sandvik, are trying to solve this problem by using more and more technically advanced machines such as the MT720 roadheader provided with remote manual (or automatic if necessary) control of the cutterhead movement along the preset trajectory. In this way, ineffective movements of the cutterhead are eliminated, and the excavation profile accuracy can be monitored on an ongoing basis (Fig. 6). 

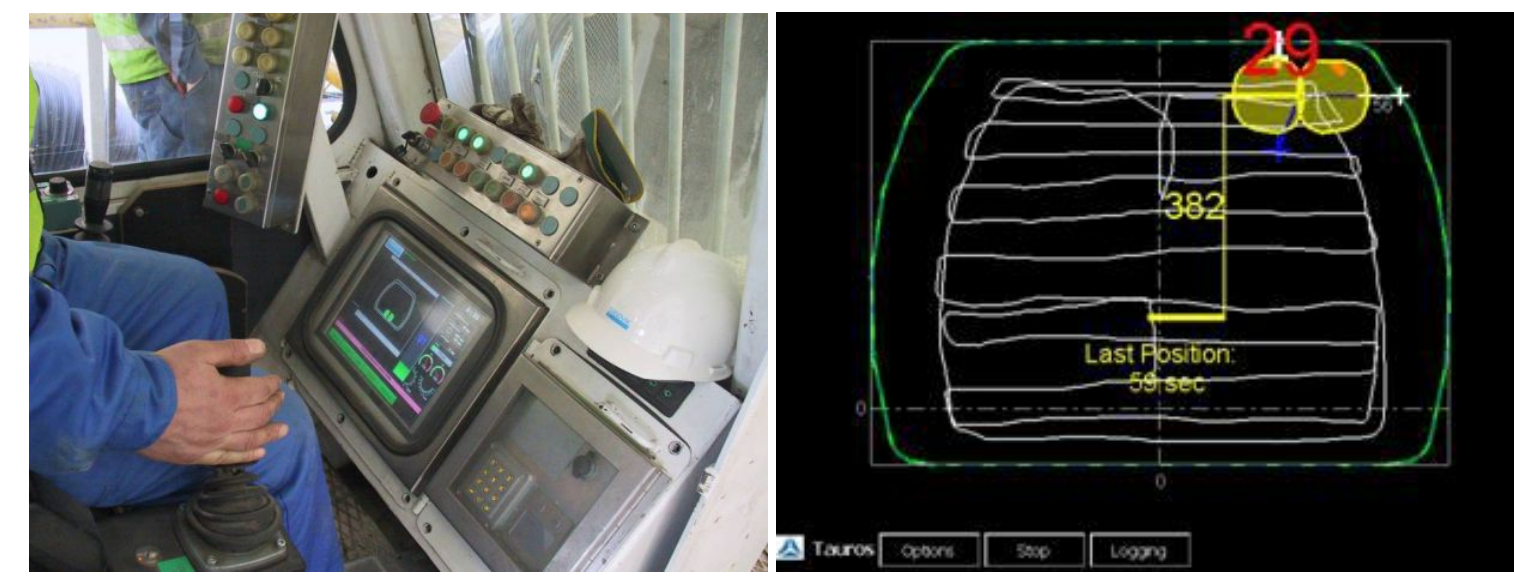

Fig. 6. Operator's control desk in a new roadheader and the display showing the cutterhead's current position (e.g. [Lammer E.: New Developments in Roadheaders. Technology Innovation Underground Construction- TUNCONSTRUCT workshop, May 26, 2009])

The software used for this purpose makes it possible to generate a current image of the excavation crosssection and compare it with the designed one. As a result of the sequential capture of images showing individual sections of the excavation, the system can also generate a "pseudo-3D" image of this excavation.

In order to adapt control systems to variable mining conditions, new methods are developed to track changes in excavating tool power consumption, simulate the variability of energy parameters, and establish control system procedures enabling the adaptation of the roadheader operating parameters to local mining conditions. Geological examination and rock mechanics data are used to predict the machinery performance (power consumption) already at the stage of the excavation process design. To this end, an algorithm for back analysis of the specific energy during cutting was developed, among other things (Fig. 6).
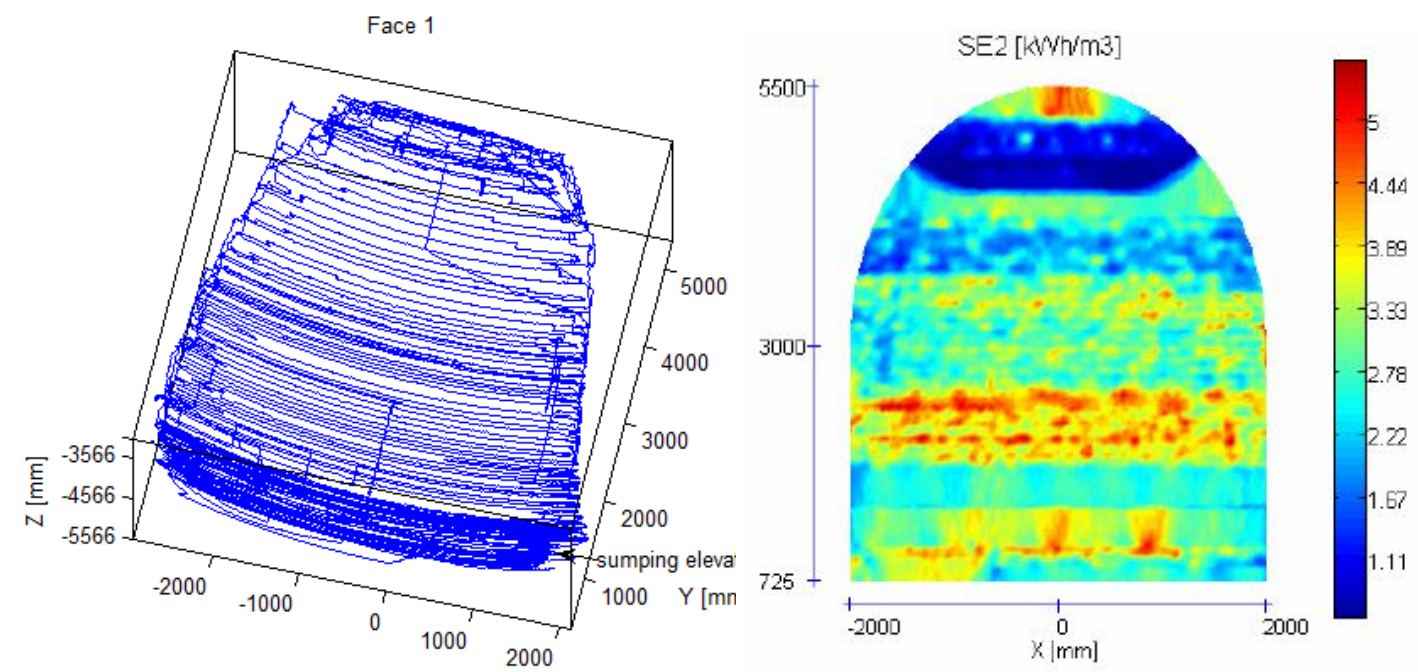

Fig. 6. Roadheader power consumption in the cross-section of the excavation [Lammer E.: New Developments in Roadheaders Technology Innovation Underground Construction- TUNCONSTRUCT workshop, May 26, 2009]

By mounting a power converter in the drive system of the cutterhead, it is possible to generate a map of roadheader power consumption in the cross-section of the excavation. When correlated with the cutterhead's momentary position (its trajectory), these data can be used to predict optimal operating parameters of the cutterhead.

The design of autonomous, automated mining machines requires developing and testing a number of algorithms that are crucial for designing such systems. For this reason, many numerical analyses (using FEM, DEM and LS-Dyna systems) and industrial verification tests are performed to enable, among other things, the prediction of rock strength parameters affecting the cutting tool loading, the structure's dynamics and correct selection of technological parameters of the mining process. An important problem here is the determination and monitoring of the position of the excavation machine axis relative to the axis to the tunnel, as well as the monitoring of the assumed direction of tunnelling. 


\section{Materials and Methods}

Monitoring of the condition and load of a single blade and the whole head is necessary in the view of the construction of adaptive tunnelling control systems. For the safety of the excavation processes, it is necessary to forecast the process ahead of time, by at least one forecasting step, in order to have the time necessary to recognise and evaluate the occurring phenomena and to potentially change the parameter settings of the excavation process performed by the shearer. Neural models are adaptive in nature and can be used to describe relationships changing over time. When new data appear, the process of network retraining may be carried out. This makes it possible to include in the model being created information from the latest observations. Networks used for the analysis of time series are primarily used for forecasting later values of variables based on previous values. Each pattern used in time series analysis must be created from several cases. As a result, in order to correctly design the network of the type under consideration, it is necessary to define two parameters, i.e. the range and horizon of the forecast. The first one determines how many samples with the appropriate time lag must be included in each analysed variable in order to define the network input. The forecast horizon determines the distance to which the forecast value is shifted relative to the last input value. The forecast horizon is routinely taken as one, which means that the network forecasts the next value of the variable under consideration immediately following the time period from which the signal used as an input has been sampled. The row parameter is usually freely determined by the user and determines the number of future values of the variable to be used as input information in an attempt to build a forecast. The more complicated dependence we expect, the bigger the row parameter should be. The range and horizon parameters of the forecast have an impact on the construction of the patterns used in learning and networking. Defining each pattern requires the use of a certain number of cases that occur during the training and initiation of the network. The definition of each template requires the application of a number of cases in the data set. The number of these cases depends on the parameters adopted

The problem of predicting the load and wear of excavation tools plays an important role in designing and maintaining cutterheads. (Liu et al., 2019; Küpferle, Röttger, and Theisen, 2017; Jones et al., 2017). The effective monitoring of the operation of multi-tool cutterhead knives and their replacement time depend on correct identification of the type and condition of the excavating tool cutting insert.

Fig. 7 shows the examples of typical excavating tools mounted in the multi-tool cutterhead that were analysed in the experimental tests.
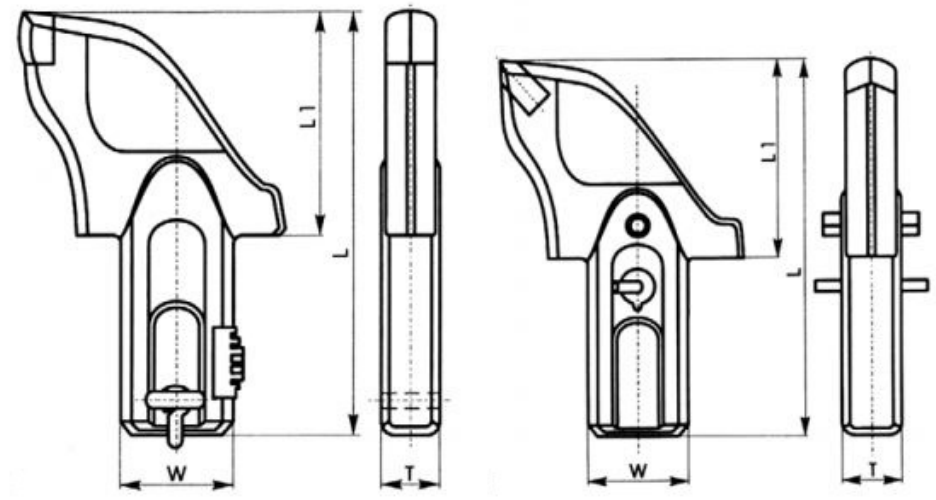

Fig. 7. Design of an excavating tool: Rapid 89-63-20wz, Rapid 84-27

The analysis of the time course of the blade load (Fig. 8) shows a very high dynamics of change of the cutting force over time. This is the main reason for the obtained value of the forecast error. In order to increase the effectiveness of the forecasting of the cutting tool's blade load and, as a result, of the whole head (the total effect of processes on each blade), it is necessary to further test the network in terms of optimal selection of both the order and the forecast horizon. This is due to the very complex course of the cutting force over time.

Fig. 8 shows the time variations of the cutting force of the Rapid 83 mining tool. The experiments were performed on sandstone samples using a test stand specially designed for this purpose. 


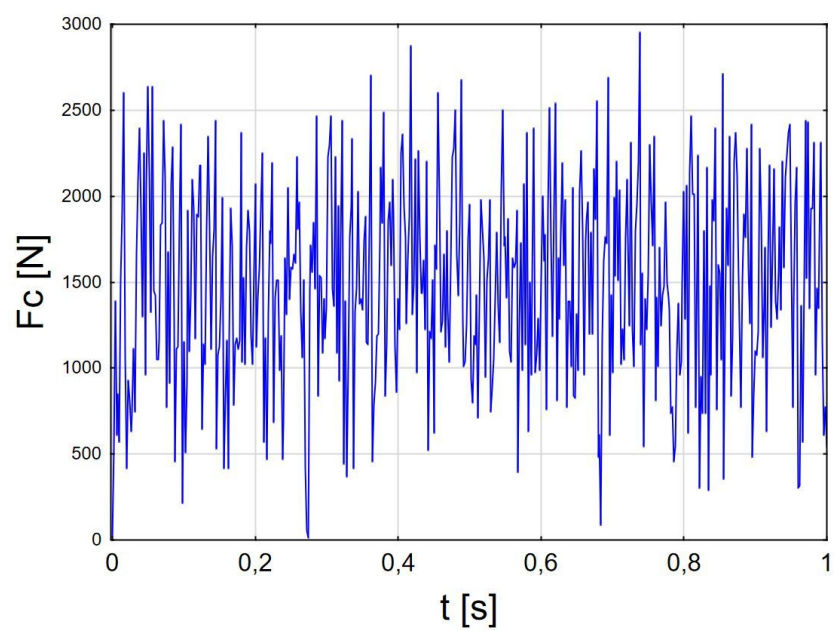

Fig. 8. Cutting force versus time

\section{Results}

Laboratory tests were performed to obtain a comprehensive database that could be used for neural network training. Neural networks are biologically inspired; they depict structures of neurons, synapses and natural nervous systems. In principle, neural networks are mathematical models for processing signals. Neural systems are called "black boxes" due to the fact that they only generate output information based on input signals. Thanks to numerical analyses, we can calculate, among other things, errors or other parameters of the model. Also, it is possible to obtain results without resorting to a complicated mathematical apparatus.

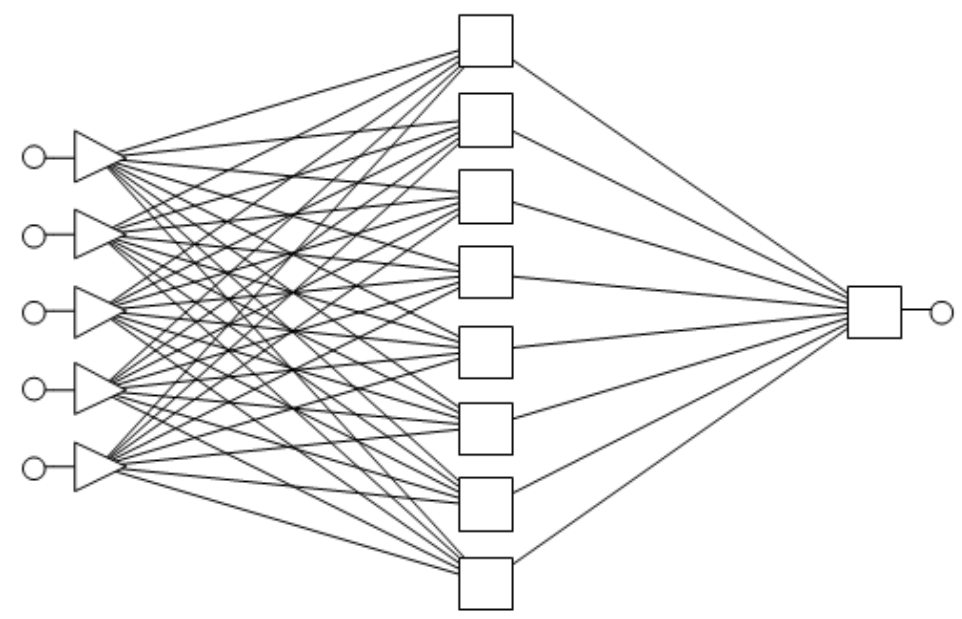

Fig. 9. Multilayer perceptron (MLP) neural network

The numerical analysis was performed using one of the most popular network models: a sigmoidal neural network in the form of a multilayer perceptron (Fig. 9). The concept of this network type is based on the arrangement of neurons in successive layers. The neurons calculate the weighted sum of their inputs, and the parameters determined in this way are the arguments of the activation function that calculate output values of successive neurons. Neurons have unidirectional structures without feedback. This neural network type is treated as an input-output model. Its parameters include weights and threshold values.

The aim of multilayer perceptron training is to determine the weight values of individual layers and thus to obtain for a given input vector the output signals that correspond as accurately as possible to the input values. The output signal of the hidden layer neuron can be described as:

$$
u_{i}=f\left(\Sigma v_{i j} y_{j}\right)
$$

Fig. 10 shows the time variation of the cutting force as well as the cutting force prediction using a multilayer perceptron with eight neurons in the hidden layer. 


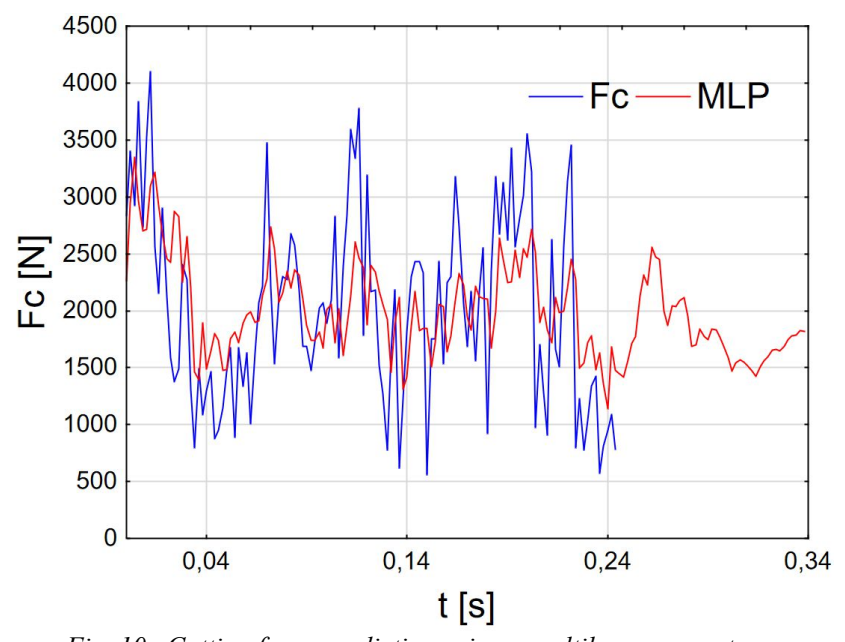

Fig. 10. Cutting force prediction using a multilayer perceptron

\section{Discussion}

The loads and condition of the cutting tool blade of the tunnel machine's working head influence its total load. Monitoring the condition of a single tool's blade is necessary to assess the entire multi-tool head condition.

The matching of the numerically generated time series to that obtained in the experimental tests is not a very demanding task when it comes to the problem of regression using artificial neural networks. A literature review shows that many studies of this type have also been carried out in the field of technical sciences. However, a great challenge is to model a neural network that would be able to make forward predictions of complicated time series. A well-matched prediction horizon allows for taking action in the event of unforeseen circumstances, e.g. failure.

An analysis of the prediction covering the last part of the plot in Fig. 10, containing 0.1 seconds of the time series generated by the neural network based on training and validation datasets, demonstrates that this tool can be used for monitoring time variations of the cutting force. The network can practically forward predict any number of values, going beyond the previously available data. Obviously, the matching is not perfect, and some signal averaging is visible. Nevertheless, as previously mentioned, the possibility of making such predictions seems promising in the context of catastrophic event identification.

The neural perceptron was designed in such a way as to prevent network overfitting. This phenomenon could be caused by ideal representation of the existing time course - the time series would be point by point almost identical to the recorded one, while in the case of making a prediction, the data would immediately take unreliable values. This phenomenon is quite common, therefore - in the opinion of the authors the usefulness of the predicted time series can only be assessed on the basis of the model's ability to go beyond available data, and not its ability to fit to the existing time-course data. The neural network during the learning process may find itself a non-linear model of the system under consideration.

The use of multilayer perceptron-based models, and especially non-linear models, therefore significantly increases the modelling possibilities. On the basis of the results obtained, it is possible to confirm the effectiveness of the proposed method of forecasting the condition of tool blades.

\section{Conclusion}

Currently, the worldwide use of a shield tunnel boring machine in tunnel excavation is continuously increasing. TBM is a widely used tunnel boring technique that is safe for nearby engineering structures is the use of tunnel boring machines. A Rock Tunnel Boring Machine provides high advance rates and excellent working safety. It also reduces the extent of the damaged zone beyond the planned excavation limit compared with the traditional D\&B method.

The tests carried out on the laboratory stand correspond to the conditions of actual mining. In the bench tests, the tools actually used in mining were used. The recorded cutting force signals correspond to the actual conditions. Artificial neural networks are an excellent tool for modelling non-linear phenomena. The multilayer perceptron used made it possible to forecast the cutting force of a mining tool. The prediction of tool load is important from the point of view of the safety of a multi-tool head. Effective blade load forecasting can prevent catastrophic wear.

This paper discussed the problem of predicting load on the cutting tools in tunnel boring machines. The paper raised interdisciplinary aspects combining the problem of transport infrastructure creation with 
environmental engineering and mining. The publication contains the results of laboratory tests and using Statistica software.

The paper proposed a method for predicting time variations of the cutting force of a multi-tool cutterhead tool using an artificial neural network. The effectiveness of the proposed test method has been confirmed numerically. The network's behaviour is satisfactory, with the nonlinearities and oscillations being maintained. Although the proposed method requires further numerical analyses, it can already be claimed that the method can serve as a basis for developing assumptions of a project on monitoring the operation of such systems.

\section{References}

AutoMine. Sandvik Mining and Construction - www.

Bołoz, Ł. (2018) 'Model tests of longwall shearer with string feed system', Archives of Mining Sciences, 63(1), pp. 61-74. doi: 10.24425/118885.

Bołoz, Ł. and Midor, K. (2018) 'Process innovations in the mining industry and the effects of their implementation presented on the example of longwall milling heads', Acta Montanistica Slovaca, 23(3), pp. 282-292.

Bołoz, Ł. and Midor, K. (2019) 'The procedure of choosing an optimal offer for a conical pick as an element of realising the sustainable development concept in mining enterprises', Acta Montanistica Slovaca, 24(2), pp. $140-150$.

Bołoz, Ł. (2020) 'Interpretation of the results of mechanical rock properties testing with respect to mining methods', Acta Montanistica Slovaca, 25(1), pp. 81-93.

Bracewell R.H., Bradley D.A., Chaplin R.V., Seward D.W.: Control system design for a robotic backhoe. wwwedc.eng.cam.ac.uk/ rhb24/isarc90.pdf

Cheluszka P., Dolipski M., Sobota P. (2017): Significance of cutting process parameters as related to improving dynamic state of roadheader and minimising power consumption. Mining- informatics, Automation and Electrical Engineering, No. 2 (530) http://dx.doi.org/10.7494/miag.2017.2.530.59

Cheluszka P., Plaszczymąka D. (2019): Analysis of the intensity of vibrations of a boom-type roadheader generated by a cutting process. Maszyny Górnicze, Nr 1, https://doi.org/10.32056/KOMAG2019.1.2

Clarke-Hackston N. , Belz J., Henneker A.(2007): Guidance for Partial Face Excavation Machines. Rapid Excavation and Tunneling Conference. Proceedings. Red. M. T. Taylor, pp. 457-465.

D.J. Burger (2006): Integration of the mining plan in a mining automation system using state-of-the-art technology at De Beers Finsch Mine. The Journal of The South African Institute of Mining and Metallurgy Volume 106.

Ebrahimabadi A., Azimipour M., Bahreini A.(2015): Prediction of roadheaders' performance using artificial neural network approaches (MLP and KOSFM). Journal of Rock Mechanics and Geotechnical Engineering 7, 573-583. http://dx.doi.org/10.1016/j.jrmge.2015.06.008

Fox B. (2004): Mining and Robotics. A next new thing joins the commodities bull market. Presentation to the Northwest Mining Association

Fu L., Du Ch., Li J., Zheng K. (2015): Influence of pick working angle on cutting performance of auger miner's aiguille. Advances in Mechanical Engineering, Vol. 7(5) 1-10, DOI: 10.1177/1687814015585427

Gajewski J, Jonak J. (2011): Towards the identification of worn picks on cutterdrums based on torque and power signals using artificial neural networks, Tunn. Undergr. Space Technol. 26

Gajewski J., Jedliński Ł., Jonak J. (2013): Classification of wear level of mining tools with the use of fuzzy neural network, Tunn. Undergr. Space Technol. 35

Hasilová, K. and Gajewski, J. (2019) 'The use of kernel density estimates for classification of ripping tool wear', Tunnelling and Underground Space Technology. Elsevier, 88(August 2018), pp. 29-34. doi: 10.1016/j.tust.2019.03.001.

Jasiulek D., Świder J. (2013): Mechatronic systems in mining roadheaders - examples of solutions. Pomiary Automatyka Robotyka nr 1

Jedliński, Ł. and Gajewski, J. (2019) 'Optimal selection of signal features in the diagnostics of mining head tools condition', Tunnelling and Underground Space Technology, 84(August 2018), pp. 451-460. doi: 10.1016/j.tust.2018.11.042.

Jonak J. (2002): Possibility of neural network application for predicting the load onexcavating machines.Journal of Mining Science, 2020 38(4).

Krauze, K., Bołoz, Ł. and Wydro, T. (2015) 'Parametric factors for the tangential-rotary picks quality assessment', Archives of Mining Sciences, 60(1), pp. 265-281. doi: 10.1515/amsc-2015-0018.

Lammer E. (2009): New Developments in Roadheaders. Technology Innovation Underground ConstructionTUNCONSTRUCT workshop. 
Larsson J., Appelgren J., Marshall J., T. Barfoot T. (2008): Autonomous Underground Tramming. asrl.utias.utoronto.ca/ tdb/bib/larsson_massmin08.pdf

LEICA TMS Tunnelscan. Complete tunnel documentation. Katalog LEICA GEOSYSTEMS.

Li X., Binbing B., Ma G., Zeng Q. (2013): Study on Roadheader Cutting Load at Different Properties of Coal and Rock. The ScientificWorld Journal, 624512, http://dx.doi.org/10.1155/2013/624512

Lu Z., Wan L., Zeng Q., Zhang X., Gao K.(2017): Numerical Simulation of Fragment Separation during Rock Cutting Using a 3D Dynamic Finite Element Analysis Code. Advances in Materials Science and Engineering, Volume, 3024918, https://doi.org/10.1155/2017/3024918

PPS-RH3. Guidance System for Roadheader -Overview. Materiały Poltinger Precision Systems.

Seker E., Ocak I. (2019): Performance prediction of roadheaders using ensemble machine learning techniques. Neural Comput \& Applic 31:1103-1116. DOI 10.1007/s00521-017-3141-2

Qianqian Z., Zhennan H., Mengqi Z., Jianguang Z.(2015): Prediction of Tool Forces in Rock Cutting using Discrete Element Method. Electronic Journal of Geotechnical Engineering, Vol. 20, Bund. 5. http://www.ejge.com/2015/Ppr2015.0182ma.pdf 